\title{
Logistics Service Suppliers Evaluation Based on Fuzzy Soft Set
}

\author{
Dandan Zhang, Jie Xu \\ Beijing Jiaotong University, Beijing, China
}

Keywords: Logistics Service, Fuzzy Soft Set.

\begin{abstract}
This paper analyzes the content and scope of logistics service demand of company A, builds the evaluation indicator system of logistics service suppliers of company A, uses the fuzzy soft set to quantify and analyze the evaluation index of logistics service suppliers of company A, Established a Multi-departmental expert model evaluation system, and through the example project suppliers analysis and verification and evaluation, pointed out that company A selects a high-quality logistics service supplier is conducive to enhancing A company's logistics service capabilities, thus enhancing A's core competitiveness.
\end{abstract}

\section{Introduction}

Due to the impact of resources and the environment, the strength of each logistics suppliers also has its own length, which brings some difficulties for the selection of enterprise. Under such a background, the evaluation of enterprise logistics service suppliers has attracted great attention from academia. Enterprises are increasingly required to establish good logistics service procurement mechanism and form a benign logistics service procurement decision system.

The problem of evaluation index system is the basis of evaluation and selection of logistics service suppliers. Dickson [1] by the 273 American Association Manager Purchasing Manager and purchasing agent for investigation, analysis of sorting out 23 different criteria to evaluate the supplier's performance. STAMM and GOLHAR [2] through classification and summarizes 43 factors that affect. The supplier evaluation method is another important aspect of supplier selection theory. In the aspect of specific selection evaluation, there are the methods of AHP [3], Data Envelopment Analysis (DEA)[4], Mathematical Programming [5], Analytic Network Process [6] (ANP), Fuzzy Set Theory and so on, applied to the supplier's choice and evaluation. However, the soft set given by Molodtsov [7] has been booming in recent years due to its ability to handle uncertainties, ambiguities and objects that have not been clearly defined.

Company $\mathrm{A}$ is a designer and manufacturer of innovative microprocessors for computers, as well as flash and low-power processor solutions. Procurement of logistics services is a guarantee of the entire company's production and plays a crucial role in supporting the normal operation of the entire company. However, the main problems of A's logistics service procurement are ignoring the differences in the demand of different departments for the indicators and subjective model evaluation.

In this paper, to solve the first problem, the fuzzy soft set can be used to adapt to the advantages of different indicators in different departments. According to the opinions of experts from all departments, a reasonable and comprehensive index for all departments is established to improve the rationality of the index system. For the second problem, fuzzy soft set operation and evaluation rules are introduced. Evaluate the uncertain factors in the process of soft set operation. Avoid the problem of membership degree of the traditional fuzzy comprehensive judgment, the judgment result is more scientific and reasonable.

\section{Evaluation Indicator}

The logistics service content of Company A is relatively simple, but the logistics and transportation requirements are relatively high, which includes not only providing inter city logistics services to the core products of the company, but also putting forward requirements for time and transport safety. 
According to the actual situation of company A, and considering many scholars in the selection of logistics suppliers evaluation indicator system. The finalized indicator system includes cost index, quality index, technical index, service index and flexibility indicator. Each indicator is divided into different secondary indicators. Table 1 shows the specific circumstances.

TABLE 1. LOGISTICS SER VICE SUPPLIER EVALUTION INDICATOR SYSTEM

\begin{tabular}{|c|c|c|}
\hline \multirow{16}{*}{$\begin{array}{c}\text { Supplier } \\
\text { comprehensive } \\
\text { evaluation } \\
\text { index system } \\
\text { A }\end{array}$} & \multirow{3}{*}{ Cost Indicator B1 } & Vendor Quote C1 \\
\hline & & Payment method C2 \\
\hline & & Payment term C3 \\
\hline & \multirow{3}{*}{$\begin{array}{l}\text { Flexibility } \\
\text { Indicator B2 }\end{array}$} & Contingency Planning and Options C4 \\
\hline & & Response time C5 \\
\hline & & National Transport Support C6 \\
\hline & \multirow{4}{*}{ Specifications B3 } & $\begin{array}{c}\text { Vehicle Characteristics and } \\
\text { Global Positioning System Capability C7 }\end{array}$ \\
\hline & & Free Trade Zone warehouse safety facilities C8 \\
\hline & & Integrated Information Platform C9 \\
\hline & & Construction of logistics network C10 \\
\hline & \multirow{3}{*}{ Quality Index B4 } & Warehouse Management C11 \\
\hline & & ISO9001 certification C12 \\
\hline & & $\begin{array}{l}\text { Well-known company's recognition of supplier logistics } \\
\text { projects C13 }\end{array}$ \\
\hline & \multirow{3}{*}{$\begin{array}{l}\text { Service(Customer } \\
\text { Support) Indicator } \\
\text { B5 }\end{array}$} & Project Management Team C14 \\
\hline & & Professional Services Team C15 \\
\hline & & Corporate culture match degree $\mathrm{C} 16$ \\
\hline
\end{tabular}

\section{Evaluation Model}

Blurry soft collection

Definition 1 Soft collection. Let $U$ be the initial universe of discourse, E be the parameter set, $P(U)$ be the power set of the set $U,(F, E)$ be a soft set on the universe $U$ if and only if $F$ is $E$ to $P(U)$ a map.

For $\forall \varepsilon \in E, F(\varepsilon)$ is a set of elements in $U$ with $\varepsilon$-parameter property, that is, $F(\varepsilon) \in U$, and the soft set $(F, E)$ is a set of elements with properties of each parameter in $U$ Constitute the approximate set..

Definition 2 Fuzzy soft collection. Let $U$ be the initial domain, $E$ be a parameter set, $\varphi(U)$ be a fuzzy set of a set $U, C \in E,(F, C)$ be a fuzzy soft set on the universe $U$, if and only if $F$ is $C$ A mapping to $\varphi(U)$.

Definition 3 Fuzzy set "AND" operation. Let $\left(F_{1}, C\right)$ and $\left(F_{2}, D\right)$ be two fuzzy soft sets on $U$, and if $\forall(\alpha, \beta) \in C \times D, H(\alpha, \beta)=F_{1}(\alpha) \cap F_{2}(\beta)$, Then $\left(F_{1}, C\right) \wedge\left(F_{2}, D\right)=(F, C \times D)$ is the AND operation of $\left(F_{1}, C\right)$ and $\left(F_{2}, D\right)$.

Service Purchasing Supplier Evaluation Model

Logistics service supplier evaluation of uncertainty in the expression of information

Evaluation of the various indicators of logistics services, the characteristics of the evaluation using the following level to represent that

$$
H=\{0,0.1,0.2,0.3,0.4,0.5,0.6,0.7,0.8,0.9,1.0\}
$$

The evaluation value $v$ The larger, indicating that the more suppliers of the indicators meet the requirements.

Logistics service supplier evaluation process 
To solve the problem of logistics service procurement supplier evaluation, we first provide the collection of logistics suppliers to be evaluated $U=\left\{h_{1}, h_{2}, \cdots, h_{n}\right\}$ and the evaluation index set $C=\left\{e_{1}, e_{2}, \cdots, e_{m}\right\}$ The evaluation index set $C_{1}=\left\{e_{1}, e_{2}, \cdots, e_{m}\right\}$ is given and the evaluation matrix $V_{N^{*} t}$ is given. Finally, the fuzzy evaluation set is used to fuse the evaluation values of experts from different departments to get the final evaluation result .

According to the experts in different departments, the evaluation information of their personal index set $C_{k}$ and evaluation matrix $V_{N^{*} k_{t}}$ is expressed as fuzzy soft set $\left(F_{k}, C_{k}\right)$ that

$$
\left(F_{k}, C_{k}\right)=\left\{\begin{array}{l}
C_{1}^{k}=\left\{h_{1} / v_{11}^{k}, h_{2} / v_{12}^{k}, \cdots, h_{n} / v_{1 n}^{k}\right\} \\
C_{2}^{k}=\left\{h_{1} / v_{21}^{k}, h_{2} / v_{22}^{k}, \cdots, h_{n} / v_{2 n}^{k}\right\} \\
\cdots \\
C_{k_{t}}^{k}=\left\{h_{1} / v_{k_{t}}^{k}, h_{2} / v_{k_{t}}^{k}, \cdots, h_{n} / v_{k_{t} n}^{k}\right\}
\end{array}\right.
$$

After the evaluation information of experts in different departments are merged, the company's comprehensive evaluation matrix for suppliers can be obtained. The fusion method is as follows: ("AND" is performed on the fuzzy soft sets $\left(F_{k}, C_{k}\right)$ in turn, and the result is represented by $(G, E)$ )

$$
(G, E)=\left(G, C_{1} \times C_{2} \times \cdots \times C_{t}\right)=\left(F_{1}, C_{1}\right) \wedge\left(F_{2}, C_{2}\right) \wedge \cdots \wedge\left(F_{t}, C_{t}\right)
$$

For $\forall\left(c_{1}^{\bullet}, c_{2}^{\bullet}, \cdots, c_{s}^{\bullet}\right) \in C_{1} \times C_{2} \times \cdots \times C_{t}$, the result is represented that

$$
G\left(c_{1}^{\bullet}, c_{2}^{\bullet}, \cdots, c_{s}^{\bullet}\right)=F_{1}\left(c_{1}\right) \cap F_{2}\left(c_{2}\right) \cap \cdots \cap F_{t}\left(c_{t}\right)
$$

$(G, E)$ is also a fuzzy soft set. From the definition three we can see $(G, E)$ in the parameters by different evaluation experts fuzzy evaluation index set $C_{1}, C_{2}, \cdots, C_{t}$ synthesized. If there is a total of parameters for $\mathrm{L}$ synthesis in $(G, E)$ and $E=\left\{e_{1}, e_{2}, \cdots, e_{L}\right\},(G, E)$ can be expressed that

$$
(G, E)=\left\{\begin{array}{l}
e_{1}=\left\{h_{1} / v_{11}, h_{2} / v_{12}, \cdots, h_{n} / v_{1 n}\right\} \\
e_{2}=\left\{h_{1} / v_{21}, h_{2} / v_{22}, \cdots, h_{n} / v_{2 n}\right\} \\
\cdots \\
e_{L}=\left\{h_{1} / v_{L 1}, h_{2} / v_{L 2}, \cdots, h_{n} / v_{L n}\right\}
\end{array}\right\}
$$

In the formula, $v_{i j}$ represents the degree of conformity of the supplier $h_{j}$ to the state described by the synthesized parameter $e_{i}(i=1,2, \cdots, L)$ and $L=l_{1} * l_{2} * \ldots * l_{t}$. However, if the final set of parameters has the same element set, the average of the first set is obtained when the set of indicators are aggregated, and then the minimum value of the different indicators is taken. At this point, the parameter set $E$ is composed of individual indicators from different departments and experts free combination.

Let $c_{k} \in C_{K}$, and if $v_{c_{i}}$ and $v_{c_{j}}$ are different experts score the same indicator, then

$$
v_{c_{i}}=v_{c_{j}}=1 / 2\left(v_{c_{i}}+v_{c_{j}}\right)
$$

After obtaining the average value, the set of indicators is combined for set calculation, that is

$$
v_{c_{1} \cdots c_{t}}=\min _{k=1 \cdots t}\left\{v_{c_{k}}\right\} \quad c_{k} \in C_{K}
$$

After obtaining $(G, E)$, compare each supplier's score on the post-fusion impact factor to obtain a comparison-table (CT), $C T=\left(c t_{i j}\right)_{n \times L}$, where

$$
\begin{gathered}
c t_{i j}=\sum_{x} \gamma_{i j}^{x} \\
\gamma_{i j}^{x}= \begin{cases}1 & v_{i x} \geq v_{i x} \\
0 & v_{i x}<v_{i x}\end{cases}
\end{gathered}
$$


$c t_{i j}$ means that for all the synthetic evaluation parameters, the supplier $h_{i}$ comprehensive evaluation value is equal to or higher than the number of suppliers $h_{j}$.

Finally, according to CT calculation of the total score $\operatorname{Score}(h)$, that is

$$
\left\{\begin{array}{l}
\operatorname{Score}\left(h_{i}\right)=s_{i}-t_{i} \\
s_{i}=\sum_{j=1}^{n} c t_{i j}, t_{i}=\sum_{j=1}^{n} c t_{j i}
\end{array}\right.
$$

$s_{i}$ denotes the total number of suppliers $h_{i}$ which is superior to other suppliers in the composite score, $t_{i}$ denotes that the suppliers $h_{i}$ are inferior to the total number of other suppliers in the overall score, at this time, $\operatorname{Score}\left(h_{i}\right)$ characterizes the suppliers $h_{i}$ comprehensive competitiveness.

\section{Case Analysis}

Based on the characteristics of 2.1 logistics service suppliers, the four companies that are bidding are evaluated. In this model, we use the index system in 2.2 as the evaluation index library, and then choose the right supplier.

There are 4 suppliers to be evaluated $U=\left\{h_{1}, h_{2}, h_{3}, h_{4}\right\}$, the indicator set is $C=\left\{c_{1}, c_{2}, \cdots, c_{16}\right\}$ represents the indicator system in 2.2; Company A's finance, security, procurement and demand Department experts evaluate suppliers, namely: $E x=\left\{e x_{1}, e x_{2}, e x_{3}, e x_{4}\right\}$.

(1) According to the department's existing knowledge and experience, each expert gives the personal evaluation index set, that is, $C_{1}=\left\{c_{1}, c_{2}, c_{3}\right\} \quad C_{2}=\left\{c_{7}, c_{8}, c_{9}, c_{10}, c_{11}, c_{12}, c_{13}\right\}$, $C_{3}=\left\{c_{1}, c_{5}, c_{11}, c_{12}, c_{13}, c_{14}, c_{15}, c_{16}\right\}, C_{4}=\left\{c_{1}, c_{4}, c_{5}, c_{6}, c_{7}\right\}$.

(2) The evaluation matrices $V_{1}, V_{2}, V_{3}$ and $V_{4}$ are expressed as fuzzy sets $\left(F_{1}, C_{1}\right),\left(F_{2}, C_{2}\right)$, $\left(F_{3}, C_{3}\right)$ and $\left(F_{4}, C_{4}\right)$.

(3) Information fusion of $V_{1}, V_{2}, V_{3}$ and $V_{4}$ by fuzzy soft sets, that is, the result of AND of fuzzy sets $\left(F_{1}, C_{1}\right),\left(F_{2}, C_{2}\right),\left(F_{3}, C_{3}\right)$ and $\left(F_{4}, C_{4}\right)$ Calculate the score of 840 fusion indicators, that is

$$
(G, E)=\left(G, C_{1} \times C_{2} \times C_{3} \times C_{4}\right)=\left(F_{1}, C_{1}\right) \wedge\left(F_{2}, C_{2}\right) \wedge\left(F_{3}, C_{3}\right) \wedge\left(F_{4}, C_{4}\right)
$$

The parameters in $\mathrm{E}$ are shown in TABLE II:

TABLE II. COMBINATORIAL INDEX SET E IN THE PARAMETER

\begin{tabular}{|c|c|c|c|c|c|c|c|c|}
\hline$E$ & $e_{1}$ & $e_{2}$ & $e_{3}$ & $e_{4}$ & $e_{5}$ & $e_{6}$ & $e_{7}$ & $\cdots$ \\
\hline$P$ & $c_{1} c_{7} c_{1} c_{1}$ & $c_{1} c_{4} c_{1} c_{4}$ & $c_{1} c_{7} c_{1} c_{5}$ & $c_{1} c_{7} c_{1} c_{6}$ & $c_{1} c_{7} c_{1} c_{7}$ & $c_{1} c_{7} c_{5} c_{1}$ & $c_{1} c_{7} c_{5} c_{4}$ & $\cdots$ \\
\hline
\end{tabular}

According to the formula to calculate the fuzzy set $(G, E)$. Taking the fusion index of $e_{7}$ and $e_{6}$ of supplier $h_{1}$ as an example, the calculation process of $(G, E)$ is illustrated that

$$
\begin{aligned}
& e_{7}=\min \left\{v_{11}^{1}, v_{11}^{2}, v_{21}^{3}, v_{21}^{4}\right\}=\min \{0.9,0.8,0.8,0.9\}=0.8 \\
& e_{6}=\min \left\{\text { ave }\left\{v_{11}^{1}, v_{11}^{4}\right\}, v_{11}^{2}, v_{21}^{3}\right\}=\min \{0.9,0.8,0.9\}=0.8
\end{aligned}
$$

By analogy, you get the fuzzy set $(G, E)$, which is shown in the tabular form.

TABLE III. COMBINED INDEX SET E SCORES

\begin{tabular}{|c|c|c|c|c|c|c|c|c|}
\hline & $e_{1}$ & $e_{2}$ & $e_{3}$ & $e_{4}$ & $e_{5}$ & $e_{6}$ & $e_{7}$ & $\cdots$ \\
\hline$h_{1}$ & 0.8 & 0.8 & 0.8 & 0.7 & 0.7 & 0.8 & 0.8 & $\cdots$ \\
\hline$h_{2}$ & 0.6 & 0.6 & 0.6 & 0.5 & 0.6 & 0.5 & 0.5 & $\cdots$ \\
\hline$h_{3}$ & 0.7 & 0.7 & 0.6 & 0.6 & 0.7 & 0.6 & 0.6 & $\cdots$ \\
\hline$h_{4}$ & 0.7 & 0.7 & 0.7 & 0.6 & 0.65 & 0.7 & 0.7 & $\cdots$ \\
\hline
\end{tabular}

(4) The final evaluation score is calculated according to fuzzy rules. The comparison matrix is given as follows. 


$$
C T=\left\{\begin{array}{llll}
840 & 830 & 784 & 751 \\
204 & 840 & 653 & 169 \\
153 & 574 & 840 & 190 \\
512 & 827 & 790 & 840
\end{array}\right\}
$$

Then calculate final evaluation $\operatorname{Score}(H)$, that is

$$
\operatorname{Score}(H)=\left\{\begin{array}{llll}
1496 & -1205 & -1310 & 1019
\end{array}\right\}
$$

Therefore, the supplier $h_{1}$ is the best, followed by $h_{4}, h_{2}, h_{3}$.

As can be seen from the above example, the method of this paper considers that different departments consider different sets of indicators, and experts evaluate suppliers with uncertain information so that evaluation experts can flexibly express personal judgment and introduce fuzzy sets to experts. The evaluation results are integrated to obtain the comprehensive evaluation results.

\section{Conclusion}

This paper mainly uses the fuzzy soft set logistics service procurement supplier evaluation model, the qualitative analysis and quantitative analysis, according to the established Company A logistics supplier evaluation index system, through the soft set operation, the fuzzy soft set and suppliers in combination, the evaluation of logistics suppliers based on fuzzy soft aggregation is realized, which provides a reference for Company A to face how to choose logistics suppliers.

\section{References}

[1] Dickson G W. An Analysis of Vendor Selection Systems and Decision[J]. Journal of Purchasing, 1966, 2(15):1377-1382.

[2] STAMM, C. L., GOLHAR, D. Y. JIT purchasing: attribute classification and literature review [J]. Production Planning \& Control, 1993, 4(3): 273-282.

[3] Yuxing Zheng. Study on Evaluation of Ports' Third Party Logistics Service Supplier Selection Based on Analytic Hierarchy Process [J]. Logistics technology, 2017, 36(1):54-56.

[4] Zhizong Chen. Supplier Evaluation Based on Super Efficiency Context-Dependent DEA Model [J]. Industrial Engineering and Management,2013,18(5);6-12.

[5] Weihua Gan,Han Zhang. Supplier Selection of Multistage Logistics Service Supply Chain in Automobile Manufacturing [J]. Modern manufacturing engineering,2015(2):

[6] Linli Meng, Ning Zheng, Qin Wang. Research on BP Neural Network Supplier Evaluation Model Based on Genetic Algorithm [J]. Logistics Technology, 2015, 34(14):199-201.

[7] Molodtsov D. Soft set theory-First results[J]. Computers \& Mathematics with Applications, 1999, 37(4-5):19-31. 